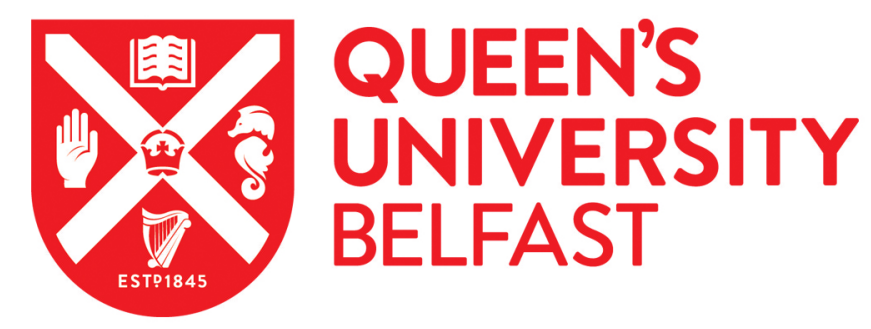

\title{
Uptake of atrazine and cadmium from soil by maize (Zea mays L.) in association with the arbuscular mycorrhizal fungus Glomus etunicatum
}

Huang, H. L., Zhang, S. Z., Chen, B. D., Wu, N. Y., Shan, X. Q., \& Christie, P. (2006). Uptake of atrazine and cadmium from soil by maize (Zea mays L.) in association with the arbuscular mycorrhizal fungus Glomus etunicatum. Journal of Agricultural and Food Chemistry, 54(25), 9377-9382. https://doi.org/10.1021/jf061699g

Published in:

Journal of Agricultural and Food Chemistry

Queen's University Belfast - Research Portal:

Link to publication record in Queen's University Belfast Research Portal

\section{General rights}

Copyright for the publications made accessible via the Queen's University Belfast Research Portal is retained by the author(s) and / or other copyright owners and it is a condition of accessing these publications that users recognise and abide by the legal requirements associated with these rights.

\section{Take down policy}

The Research Portal is Queen's institutional repository that provides access to Queen's research output. Every effort has been made to ensure that content in the Research Portal does not infringe any person's rights, or applicable UK laws. If you discover content in the Research Portal that you believe breaches copyright or violates any law, please contact openaccess@qub.ac.uk. 


\title{
Uptake of Atrazine and Cadmium from Soil by Maize (Zea mays L.) in Association with the Arbuscular Mycorrhizal Fungus Glomus etunicatum
}

\author{
Honglin Huang, ${ }^{\dagger}$ Shuzhen Zhang, ${ }^{*},{ }^{\dagger}$ Bao-Dong Chen,${ }^{\dagger}$ Naiying Wu,${ }^{\dagger}$ \\ Xiao-Quan Shan, ${ }^{\dagger}$ and Peter Christy ${ }^{\S}$
}

State Key Laboratory of Environmental Chemistry and Ecotoxicology, Research Center for Eco-Environmental Sciences, Chinese Academy of Sciences, P.O. Box 2871, Beijing 100085, China, and Agricultural and Environmental Science Department, Queen's University Belfast, Newforge Lane, Belfast BT9 5PX, United Kingdom

\begin{abstract}
A greenhouse pot experiment was carried out to investigate the effect of the arbuscular mycorrhizal fungus Glomus etunicatum on the uptake of atrazine (ATR) and cadmium (Cd) from soil by maize (Zea mays L.). Mycorrhizal colonization led to an increase in the accumulation of Cd and ATR in maize roots but a decrease in the shoots. Atrazine alleviated the adverse effects of $\mathrm{Cd}$ on maize growth, and this was more pronounced in the inoculated plants. An increase in Cd accumulation by maize roots was observed when ATR was also present. After harvest, the residual ATR concentration in the soil decreased markedly. With mycorrhizal inoculation the amount of residual ATR decreased more in the bulk soil but less in the rhizosphere soil compared to the noninoculated controls. Cadmium application significantly decreased the ATR residual concentrations in both the rhizosphere and bulk soils irrespective of inoculation treatment.
\end{abstract}

KEYWORDS: Atrazine; cadmium; arbuscular mycorrhizal fungus; maize; phytoremediation

\section{INTRODUCTION}

Heavy metals and organic contaminants often coexist in polluted soils. About $40 \%$ of the hazardous waste sites currently on the National Priority List of the U.S. Environmental Protection Agency are co-contaminated with organics and various metals (1). Therefore, to study plant uptake of pollutants or to explore phytoremediation techniques for contaminated soil cleanup, we need to consider contamination by heavy metals and organic pollutants simultaneously.

Arbuscular mycorrhizal fungi (AMF) are ubiquitous in terrestrial ecosystems, forming symbiotic associations with roots of the majority of plant species (2). Previous studies on AMF have focused mainly on plant tolerance, especially toward heavy metals and radionuclides (3-5). The ubiquity of AMF, their ability to enhance the tolerance of plants, and their interactions with soil microorganisms in the rhizosphere have recently led to the focus of attention on their interactions with organic pollutants (6). Research has established that AMF can be beneficial to the growth of several plant species in soils with high polycyclic aromatic hydrocarbon (PAH) concentrations (7). Experimental evidence for the impact of mycorrhizas on $\mathrm{PAH}$ dissipation in soils has been obtained by Joner and Leyval (8). In a recent study we also observed that the AMF Glomus

* Author to whom correspondence should be addressed (e-mail szzhang@mail rcees.ac.cn).

Research Center for Eco-Environmental Sciences.

$\S$ Queen's University Belfast. caledonium increased ATR dissipation in soil and its accumulation and metabolism in maize (9). Therefore, AMF might also exert an important influence on the uptake of organic compounds by plants.

AMF can enhance plant tolerance to both heavy metals and organic pollutants. The mechanisms related to metal uptake have been studied extensively (10-12). However, the mechanisms by which AMF influence the degradation and plant uptake of organic pollutants in soils are not clear. We might expect that the influence of AMF on uptake and mobility of metals and organics may be similar in some respects and different in others. Therefore, interactions may occur between heavy metals and organics in terms of tolerance of AMF and bioavailability of the two classes of pollutants.

Atrazine (ATR) has been widely used as a herbicide in maizegrowing areas globally, and it is still one of the most frequently detected herbicides in surface waters and groundwater $(13,14)$. Cadmium is a heavy metal that is highly toxic, and large quantities have been employed in industry and agriculture, leading to a gradual increase in $\mathrm{Cd}$ in water, soils, and food (15). Pollution by both ATR and Cd in soil has been receiving considerable attention. Their fate in soils, including toxicity and uptake by plants, has been studied extensively $(16-18)$. The effects of AMF on ATR or Cd in soil have also been investigated separately $(19,20)$, but there are no published reports of studies on interactions between AMF and co-contaminating ATR and $\mathrm{Cd}$ or any other co-contaminating organics and heavy metals. 
The aim of the present study was therefore to investigate the effects of an arbuscular mycorrhizal fungus (Glomus etunicatum) on the uptake of ATR and Cd in soil by maize and interactions between the fungus and the two contaminants. The goal was to provide information for potential phytoremediation of soils contaminated with heavy metal and organic pollutants using arbuscular mycorrhizal maize.

\section{MATERIALS AND METHODS}

Experimental Design. The experiment was a $2 \times 3 \times 3$ factorial design with mycorrhizal colonization $(+\mathrm{M} /-\mathrm{M})$ combined with atrazine-cadmium co-contamination with three concentrations of $\mathrm{Cd}(0$, 1.0 , and $5.0 \mathrm{mg}$ of $\mathrm{Cd} \mathrm{kg}^{-1}$ ) and three concentrations of added atrazine $\left(0,0.5\right.$, and $5 \mathrm{mg}$ of ATR $\left.\mathrm{kg}^{-1}\right)$. There were four replicates per treatment.

Inoculum. Inoculum of the AM fungus G. etunicatum (BGC USA01) was propagated for 10 weeks on maize plants grown in a soil-sand mixture in a greenhouse. The inoculum, comprising a sandy soil containing spores and maize root fragments, was air-dried and sieved $(<2 \mathrm{~mm})$

Soil Preparation. A brown soil (Alfisols containing 1.35\% of organic matter) was collected from the surface $(0-15 \mathrm{~cm}$ depth) of an experimental field at Beijing Academy of Agriculture and Forest Sciences. The soil was air-dried, ground, and passed through a $2 \mathrm{~mm}$ nylon sieve. The growth medium was a 1:1 (v/v) mixture of sand (1-2 $\mathrm{mm})$ and soil, which was sterilized by $\gamma$-radiation $(10 \mathrm{kGy}, 10 \mathrm{MeV}$ $\gamma$-rays) to inactivate AMF. The soil mix (henceforth referred to as the soil) had a pH of 7.89 (1: 2.5 soil/water) and a $0.5 \mathrm{M} \mathrm{NaHCO}_{3^{-}}$ extractable $\mathrm{P}$ content of $9.98 \mathrm{mg} \mathrm{kg}^{-1}$. $\mathrm{P}$ was added to the soil at a rate of $50 \mathrm{mg} \mathrm{kg}^{-1}$, and the soil was then artificially dosed with ATR and $\mathrm{Cd}$. First, the soil was spiked with $\mathrm{Cd}$ at concentrations of $0,1.0$, and $5.0 \mathrm{mg} \mathrm{kg}^{-1}$ (dry matter basis) by adding $0,18.0$, and $90.0 \mathrm{mg}$ of $\mathrm{Cd}$ as analytical grade $\mathrm{Cd}\left(\mathrm{NO}_{3}\right)_{2}$ solution to $18.0 \mathrm{~kg}$ of soil with thorough mixing. Second, batches of soil with different levels of $\mathrm{Cd}$ were divided into three portions. HPLC grade ATR (Sigma Chemical Co.) was dissolved in reagent grade acetone and added to the soil portions at concentrations of $0,0.5$, and $5.0 \mathrm{mg} \mathrm{kg}^{-1}$ (dry matter basis). The soil mix was then allowed to dry in a fume hood until the acetone had volatilized completely, shaken, homogenized, and incubated for 2 weeks to allow the co-contaminants to equilibrate.

Pot Experiment. Each pot received $650 \mathrm{~g}$ of soil. Mycorrhizal and nonmycorrhizal pots of each co-contaminant treatment were set up in quadruplicate. Mycorrhizal inoculation was carried out by mixing 60 $\mathrm{g}$ of inoculum thoroughly with the soil, and each pot contained about 2200 spores. The nonmycorrhizal controls received an equivalent amount of sterilized inoculum together with an aqueous filtrate $(0.25$ $\mu \mathrm{m}$ pore size) of unsterilized soil to provide a similar microflora except for the absence of the mycorrhizal fungus.

Maize seeds (Zea mays L.) were obtained from the Chinese Academy of Agricultural Sciences, Beijing, China. They were surface sterilized in a $10 \%(\mathrm{v} / \mathrm{v})$ solution of hydrogen peroxide for $10 \mathrm{~min}$, rinsed with sterile distilled water, and soaked in a $3 \mathrm{mM}$ solution of $\mathrm{Ca}\left(\mathrm{NO}_{3}\right)_{2}$ for $4 \mathrm{~h}$. Afterward, they were germinated on moist filter for $48 \mathrm{~h}$ prior to sowing.

Three seedlings were sown in each pot and thinned to two seedlings of uniform size. All pots were lined with polyethylene bags to avoid cross-contamination and loss of water, and the surface of each pot was covered with a black plastic bag to minimize algal growth. The experiment was conducted in a controlled-environment growth chamber that maintained a daily $14 \mathrm{~h}$ light period at a light intensity of 250 $\mu \mathrm{mol} \mathrm{m}{ }^{-2} \mathrm{~s}^{-1}$ provided by supplementary illumination. The temperature was $25^{\circ} \mathrm{C}$ at daytime and $20^{\circ} \mathrm{C}$ at night. The relative humidity was maintained at $70 \%$. The plants grew for 8 weeks. Deionized water was added as required to maintain moisture content at $60-70 \%$ of waterholding capacity. A solution of $\mathrm{NH}_{4} \mathrm{NO}_{3}$ was added 14, 21, and 24 days after sowing to provide a total of $160 \mathrm{mg}$ of $\mathrm{N}$ per pot during this growth period.

Sample Preparation. Pots were left unwatered for 1 day prior to harvest. Shoots and roots were harvested separately. Root samples were first carefully washed with tap water to remove any adhering soil particles. Then the shoot and root samples were thoroughly rinsed with distilled water, wiped with tissue paper, and immediately weighed. A subsample of fresh roots was taken from each treatment for the determination of the proportion of root length colonized by the arbuscular mycorrhizal fungus. The remaining plant samples were freeze-dried, the dry weights were recorded, and then the samples were stored at $4{ }^{\circ} \mathrm{C}$.

The bulk soil was collected by gently crushing the soil and shaking the roots (80-90\% of the soil mass). Soil that required continual vigorous rubbing and shaking of the root system was classified as rhizosphere soil $(6-10 \%$ of the soil mass) $(8)$. All of the soil samples were stored at $4{ }^{\circ} \mathrm{C}$.

Determination of Root Colonization. To estimate the proportion of total root length colonized by the fungus, a subsample of $1 \mathrm{~g}$ of fresh roots was randomly taken and cut into $0.5-1 \mathrm{~cm}$ pieces. Root segments were cleared in $10 \%(\mathrm{v} / \mathrm{v}) \mathrm{KOH}$ for $10 \mathrm{~min}$ at $90{ }^{\circ} \mathrm{C}$ in a water bath, rinsed in water, and then stained with $0.1 \%$ Trypan blue for $3-5$ min at $90{ }^{\circ} \mathrm{C}$ in a water bath. Mycorrhizal colonization was determined by the grid line intersect method (21). Briefly, subsamples of stained root segments were arranged lengthwise on a thin layer of PVA mountant on a microscope slide. A hairline graticule inserted into the eyepiece of a compound microscope acted as a line of intersection with the roots. Fungal structures at each intersection were calculated by observation at $\times 200$ magnification.

Elemental Analysis. Stored plant samples were first cut and homogenized using a mortar and pestle; $0.2 \mathrm{~g}$ of the shoot or $0.1 \mathrm{~g}$ of the root subsample was transferred into a digestion tube with the addition of a mixture of $5 \mathrm{~mL}$ of $\mathrm{HNO}_{3} / \mathrm{HClO}_{4}(4: 1 \mathrm{v} / \mathrm{v}$, ultrapure, Merck). The tube was then placed on a digestion block and heated at $100{ }^{\circ} \mathrm{C}$ until frothing stopped and then heated at $140{ }^{\circ} \mathrm{C}$ until a clear solution was obtained. The digests were then diluted to $10 \mathrm{~mL}$ with a $0.2 \%$ solution of $\mathrm{HNO}_{3}$ and analyzed for $\mathrm{Cd}$ by inductively coupled plasma-optical emission spectroscopy (ICP-OES, model OPTIMA 2000 DV, Perkin-Elmer).

Atrazine Analysis. Stored plant samples were cut and homogenized; $0.5-1.0 \mathrm{~g}$ of the samples (dry matter) was extracted twice with $50 \mathrm{~mL}$ of $80 \%$ aqueous methanol by shaking the suspension on a reciprocal shaker for $48 \mathrm{~h}$. The extracts were filtered and combined and then extracted successively with $50 \mathrm{~mL}$ of petroleum ether/dichloromethane $(65: 35, v / v)$ three times. Supernatants were passed through anhydrous $\mathrm{Na}_{2} \mathrm{SO}_{4}$ columns and collected. The volumes of eluates were reduced to $1-2 \mathrm{~mL}$. Then they were solvated with $30 \mathrm{~mL}$ of petroleum ether and re-extracted three times with $20 \mathrm{~mL}$ of acetonitrile. The acetonitrile fractions were combined, concentrated, and evaporated off. The residues were solvated with petroleum ether and cleaned with Florisil columns. The concentrations of ATR in extracts were analyzed with an Agilent 6890 gas chromatograph equipped with a detector of NPD using a HP-5 capillary column $(0.32 \mathrm{~mm} \times 30 \mathrm{~m}, 0.25 \mu \mathrm{m}$ film thickness $)$. The column oven was programmed from an initial temperature of $70{ }^{\circ} \mathrm{C}$ for $2 \mathrm{~min}$ to $220^{\circ} \mathrm{C}$ at a rate of $20^{\circ} \mathrm{C} \mathrm{min}^{-1}$, held for $1 \mathrm{~min}$, and then ramped at a rate of $4{ }^{\circ} \mathrm{C} \mathrm{min}-1$ to $240{ }^{\circ} \mathrm{C}$ with a final hold time of 10 min. The detector and injector were maintained at 300 and $250{ }^{\circ} \mathrm{C}$, respectively; the injector was in the splitless mode for nitrogenphosphorus dectection. The extraction and analysis procedures were also performed on $5.0 \mathrm{~g}$ samples of the bulk and rhizosphere soils. To determine analytical recovery, aliquots of soil were spiked with pesticides and certified reference plant materials were used. Recoveries ranged from 85 to $90 \%$ (RSD $=6.8 \%, n=5$ ).

Statistical Analysis. The data were analyzed by three-way analysis of variance using the SPSS (version 11.5) software package. Means and standard errors were calculated for four replicate values. The data were examined for the significance of AMF treatment, different levels of ATR or $\mathrm{Cd}$, and ATR/Cd/AM interactions as sources of variation.

\section{RESULTS}

Root Colonization and Plant Biomass. Table 1 displays the proportion of maize root length with mycorrhizal colonization. No mycorrhizal colonization was observed in the uninoculated plants, and the percentage of root length of inoculated 
Table 1. Mycorrhizal Colonization of Inoculated Maize Exposed to Various Concentrations of Atrazine (ATR) and Cd in the Soila

\begin{tabular}{|c|c|c|c|}
\hline \multirow[b]{2}{*}{ ATR concn $\left(\mathrm{mg} \mathrm{kg}^{-1}\right)$} & \multicolumn{3}{|c|}{ root colonization (\%) at Cd concn of } \\
\hline & $0.0 \mathrm{mg} \mathrm{kg}^{-1}$ & $1.0 \mathrm{mg} \mathrm{kg}^{-1}$ & $5.0 \mathrm{mg} \mathrm{kg}^{-1}$ \\
\hline 0 & $58 \pm 3$ & $46 \pm 5$ & $40 \pm 2$ \\
\hline 0.5 & $32 \pm 1$ & $47 \pm 1$ & $37 \pm 4$ \\
\hline 5.0 & $51 \pm 2$ & $52 \pm 3$ & $45 \pm 5$ \\
\hline significance $^{b}$ due to & & & \\
\hline inoculation treatment & & $\star \star \star *$ & \\
\hline ATR application rate & & *** & \\
\hline Cd application rate & & *** & \\
\hline inoculation $\times$ ATR & & *** & \\
\hline inoculation $\times \mathrm{Cd}$ & & $* * *$ & \\
\hline $\mathrm{ATR} \times \mathrm{Cd}$ & & *** & \\
\hline inoculation $\times \mathrm{ATR} \times \mathrm{Cd}$ & & $* * *$ & \\
\hline
\end{tabular}

${ }^{a}$ Mean \pm SE, $n=4 .{ }^{b}$ By analysis of variance; ${ }^{* * *}, p<0.001$.

plants colonized ranged from 32 to $58 \%$ on average over all of the inoculated treatments. Mean mycorrhizal root colonization decreased from $58 \%$ in Cd-free soil to 46 or $40 \%$ with 0.5 or $5.0 \mathrm{mg} \mathrm{kg}^{-1} \mathrm{Cd}$ added to the soil. The presence of ATR in the soil at a concentration of $0.5 \mathrm{mg} \mathrm{kg}^{-1}$ decreased mycorrhizal colonization, and the higher concentration (5.0 $\mathrm{mg} \mathrm{kg}^{-1}$ ) increased colonization; this was consistent with our previous observations (9). The decrease in colonization due to cocontamination with ATR and Cd was less pronounced than that with $\mathrm{Cd}$ alone $(p<0.001)$.

After 8 weeks of growth, shoot biomass was significantly affected by mycorrhizal colonization $(p<0.05)$, the inoculated roots having 1.3-2.2 times the dry weight of the uninoculated roots (Table 2). ATR application did not significantly affect the dry weights of shoots or roots $(p>0.05)$. Cadmium decreased $(p<0.001)$ the dry mass of shoots and roots compared to the control. During plant growth, leaf necrosis was evident where $5.0 \mathrm{mg} \mathrm{kg}^{-1} \mathrm{Cd}$ had been added to the soil. However, the toxicity symptoms appeared to be less severe in the presence of ATR.

Concentrations of Cadmium and Atrazine in Maize. The concentrations of $\mathrm{Cd}$ in maize are shown in Figure 1. The inoculated roots contained 1.4-3.1 times more $\mathrm{Cd}$ than uninoculated roots. In contrast, inoculation led to a reduction in $\mathrm{Cd}$ concentration in shoots by $35-69 \%$. An interesting observation
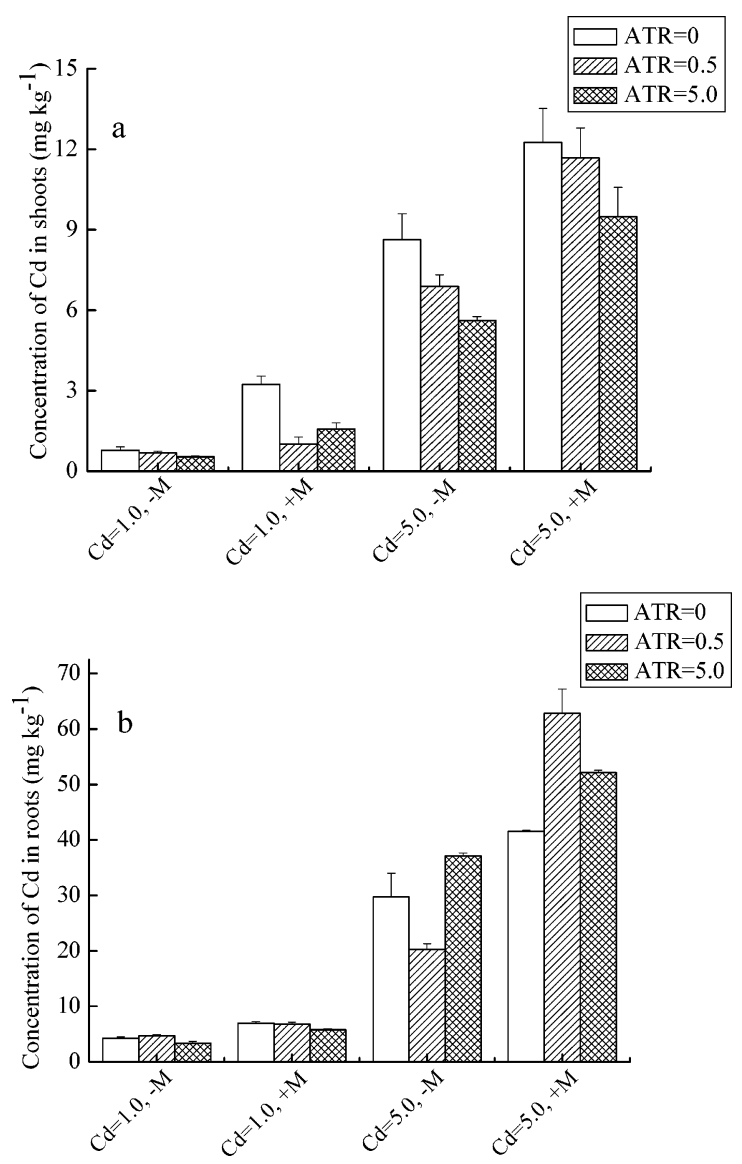

Figure 1. Cadmium concentrations (dry matter basis) in maize shoots (a) and roots (b) after cultivation for 8 weeks in uninoculated soil $(-M)$ or in soil inoculated with the arbuscular mycorrhizal fungus $G$. etunicatum $(+\mathrm{M})$ with the coexistence of ATR at $0,0.5$, and $5.0 \mathrm{mg} \mathrm{kg}^{-1}$.

was that $\mathrm{Cd}$ concentrations in the inoculated roots significantly increased with the coexistence of ATR and Cd in the soil. For instance, when $5.0 \mathrm{mg} \mathrm{kg}^{-1} \mathrm{Cd}$ was added to the soil, the $\mathrm{Cd}$ concentration in mycorrhizal roots increased by 25.6 and $51.3 \%$ when the ATR concentrations added to the soil were 0.5 and $5.0 \mathrm{mg} \mathrm{kg}{ }^{-1}$, respectively. In contrast, application of ATR at

Table 2. Biomass of Maize Shoots and Roots Cultivated in Mycorrhizal (+M) and Nonmycorrhizal $(-M)$ Soil with Various Concentrations of Added Atrazine (ATR) and Cda

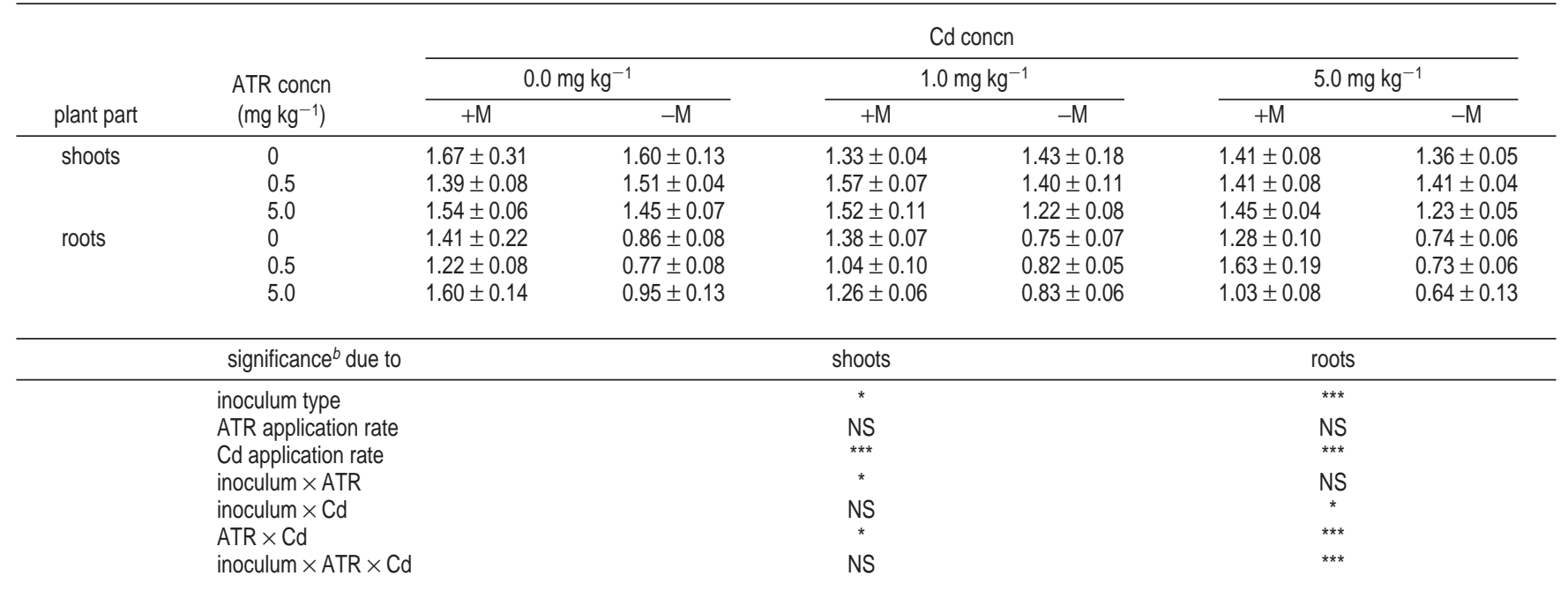

\footnotetext{
${ }^{a}$ Based on dry weight and represented as mean \pm SE, $n=4 .{ }^{b}$ By analysis of variance; ${ }^{* * *}, p<0.001 ;{ }^{*}, p<0.05 ;$ NS, not significant.
} 
Table 3. Concentrations (Milligrams per Kilogram) of Atrazine (ATR) and Its Metabolites in Mycorrhizal $(+M)$ and Nonmycorrhizal (-M) Plants ${ }^{a}$

\begin{tabular}{|c|c|c|c|c|c|c|c|}
\hline \multirow{3}{*}{$\begin{array}{l}\text { atrazine or } \\
\text { metabolite }\end{array}$} & \multirow[b]{3}{*}{ plant part } & \multicolumn{6}{|c|}{ Cd concn } \\
\hline & & \multicolumn{2}{|c|}{$0 \mathrm{mg} \mathrm{kg}^{-1}$} & \multicolumn{2}{|c|}{$1.0 \mathrm{mg} \mathrm{kg}^{-1}$} & \multicolumn{2}{|c|}{$5.0 \mathrm{mg} \mathrm{kg}^{-1}$} \\
\hline & & $+\mathrm{M}$ & $-\mathrm{M}$ & $+\mathrm{M}$ & $-\mathrm{M}$ & $+\mathrm{M}$ & $-\mathrm{M}$ \\
\hline \multirow[t]{2}{*}{ ATR } & shoots & $0.18 \pm 0.01$ & $0.41 \pm 0.02$ & $0.25 \pm 0.02$ & $0.13 \pm 0.01$ & $0.18 \pm 0.02$ & $0.05 \pm 0.01$ \\
\hline & roots & $0.78 \pm 0.02$ & $0.48 \pm 0.03$ & $1.43 \pm 0.08$ & $0.53 \pm 0.03$ & $2.25 \pm 0.18$ & $1.72 \pm 0.12$ \\
\hline \multirow[t]{2}{*}{ DEA } & shoots & $0.65 \pm 0.02$ & $1.09 \pm 0.03$ & $0.28 \pm 0.02$ & $0.55 \pm 0.01$ & $0.86 \pm 0.05$ & $0.50 \pm 0.02$ \\
\hline & roots & $4.25 \pm 0.23$ & $2.28 \pm 0.15$ & $4.13 \pm 0.26$ & $4.16 \pm 0.32$ & $9.03 \pm 0.39$ & $3.97 \pm 0.12$ \\
\hline \multirow[t]{2}{*}{ DIA } & shoots & $0.20 \pm 0.01$ & $0.35 \pm 0.01$ & $0.39 \pm 0.02$ & $0.75 \pm 0.03$ & $0.71 \pm 0.03$ & $0.38 \pm 0.01$ \\
\hline & roots & $2.46 \pm 0.15$ & $1.35 \pm 0.13$ & $6.95 \pm 0.08$ & $6.28 \pm 0.09$ & $1.26 \pm 0.09$ & $2.65 \pm 0.16$ \\
\hline \multirow[t]{2}{*}{$\mathrm{HA}$} & shoots & nd & nd & nd & nd & $1.43 \pm 0.03$ & $1.62 \pm 0.05$ \\
\hline & roots & nd & nd & nd & nd & nd & $0.90 \pm 0.01$ \\
\hline
\end{tabular}

${ }^{a}$ With $0.5 \mathrm{mg} \mathrm{kg}^{-1}$ ATR added in the soil; concentrations are expressed on a dry matter basis. nd, not detected.
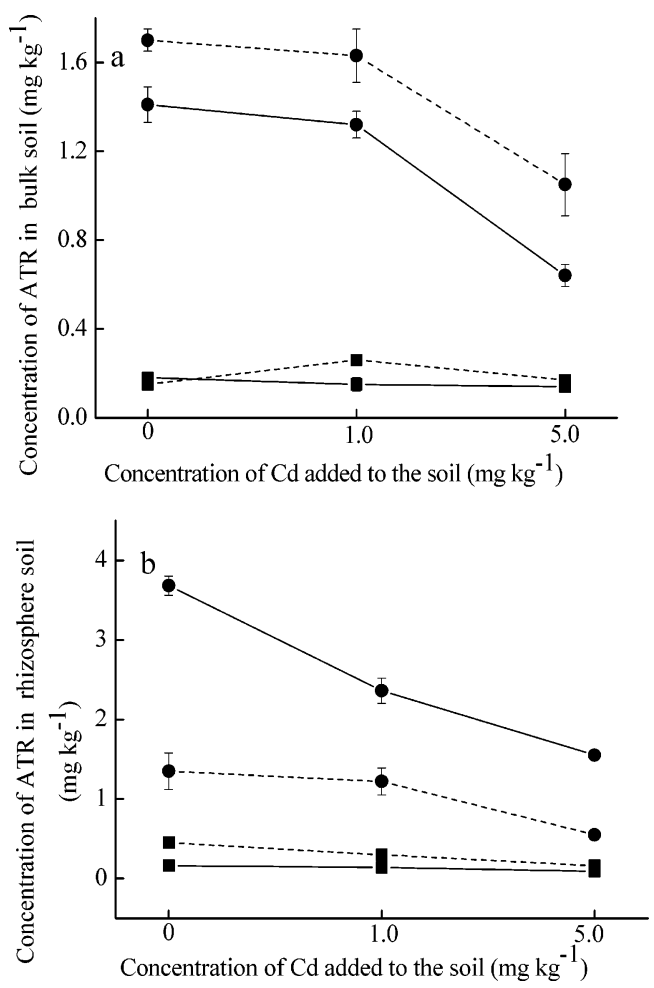

Figure 2. Residual concentrations of ATR in bulk (a) and rhizosphere soil (b) after cultivating maize for 8 weeks in the presence $(-)$ or absence (- - -) of AMF with an initial application of ATR of $0.5 \mathrm{mg} \mathrm{kg}^{-1}(\mathbf{\square})$ or 5.0 $\mathrm{mg} \mathrm{kg}$

$5.0 \mathrm{mg} \mathrm{kg}{ }^{-1}$ decreased the Cd concentration in shoots by $18.2-$ $50.5 \%$ with mycorrhizal inoculation.

Two main metabolites of ATR, deethylatrazine (DEA) (1amino-4-chloro-6-isopropylanine-s-triazine) and deisopropylatrazine (DIA) (2-amino-4-chloro-6-ethylamino-s-triazine) were detected in both shoots and roots (Table 3). Hydroxyatrazine (OH-ATR) was detected only in some treatments. In contrast, no consistent patterns were observed in the accumulation of the metabolites in maize as related to the inoculation treatments or addition of $\mathrm{Cd}$ to the soil.

Residual Atrazine in Soil. After harvest, the residual ATR concentrations in soil decreased markedly compared with the initial concentrations (Figure 2). The influence of mycorrhizal treatment was different depending on the ATR application rate and differed between bulk and rhizosphere soil. When $0.5 \mathrm{mg}$ $\mathrm{kg}^{-1}$ ATR was added to the soil, inoculation treatments significantly $(p<0.05)$ decreased the residual ATR concentrations in both the bulk and rhizosphere soils. When $5.0 \mathrm{mg} \mathrm{kg}^{-1}$ ATR was added, the amount of residual ATR in the bulk soil decreased more in mycorrhizal treatments than in nonmycorrhizal, and the opposite trend occurred in the rhizosphere soil. None of the dealkylated metabolites of ATR were detected in the soil extracts. Only OH-ATR was observed in the soil under certain treatments (data not shown)

Coexistence of $\mathrm{Cd}$ with ATR did not influence the residual amount of ATR in either the rhizosphere or bulk soil when 0.5 $\mathrm{mg} \mathrm{kg}^{-1}$ ATR was added to the soil. However, when the application rate of ATR was $5.0 \mathrm{mg} \mathrm{kg}^{-1}$, the ATR concentrations in the bulk soil decreased with increasing $\mathrm{Cd}$ concentration in both inoculated and uninoculated treatments. In addition, $\mathrm{Cd}$ application consistently decreased ATR concentrations in the rhizosphere soil irrespective of inoculation treatment.

\section{DISCUSSION}

The recommended application rate of ATR in agriculture ranges from 1.13 to $1.50 \mathrm{~kg} \mathrm{ha}^{-1}\left(0.50-0.67 \mathrm{mg} \mathrm{kg}^{-1}\right.$ of soil). Although our application rate of $5.0 \mathrm{mg} \mathrm{kg}^{-1}$ was much higher than this, ATR had no detrimental effect on maize growth, possibly due to the conversion of ATR to non-phytotoxic metabolites inside the plants (22). Increasing $\mathrm{Cd}$ concentration in the soil decreased mycorrhizal root colonization and led to leaf necrosis. When ATR and Cd coexisted, mycorrhizal root colonization increased and leaf necrosis was also alleviated. These results may perhaps be ascribed to the formation of insoluble complexes by ATR and Cd. Effects of single organics such as the insecticide dimethoate or the fungicide chlorothalonil on mycrorrhizal colonization have been examined in previous studies $(23,24)$. However, the present study is to our knowledge the first to demonstrate the interaction of $\mathrm{AMF}$ with a coexisting heavy metal and organic pollutants. Our study shows for the first time that the presence of ATR can alleviate the adverse effects on maize growth caused by $\mathrm{Cd}$, as evidenced by the data on biomass and mycorrhizal root colonization, as well as leaf necrosis.

Mycrorrhizal colonization significantly enhanced root $\mathrm{Cd}$ concentrations and decreased shoot Cd concentrations $(p<$ 0.05). A similar phenomenon was also observed for ATR, which was in agreement with our previous study (9). Furthermore, interaction between the ATR and AMF was consistent in the two AMF G. etunicatum and G. caledonium. It is important to note that there was a significant interdependence between the uptake of ATR and Cd by maize. ATR decreased Cd uptake in shoots and increased its concentration in roots, and this effect was more pronounced in mycorrhizal treatments. However, ATR concentrations in shoots decreased with the application of $\mathrm{Cd}$. This finding presumably resulted from the constrained transport of ATR in the presence of Cd. ATR contains electron-donor atoms and may form a metal-ATR complex with $\mathrm{Cd}(25,26)$, 
Table 4. Sum of the Concentrations (Milligrams per Kilogram) of Atrazine and Its Metabolites in Maize ${ }^{a}$

\begin{tabular}{|c|c|c|c|c|c|c|}
\hline \multirow[b]{3}{*}{ plant part } & \multicolumn{6}{|c|}{ Cd concn } \\
\hline & \multicolumn{2}{|c|}{$0 \mathrm{mg} \mathrm{kg}^{-1}$} & \multicolumn{2}{|c|}{$1.0 \mathrm{mg} \mathrm{kg}^{-1}$} & \multicolumn{2}{|c|}{$5.0 \mathrm{mg} \mathrm{kg}^{-1}$} \\
\hline & $+\mathrm{M}$ & $-\mathrm{M}$ & $+\mathrm{M}$ & $-M$ & $+\mathrm{M}$ & $-M$ \\
\hline shoots & 1.58 & 2.09 & 1.05 & 2.49 & 4.01 & 3.11 \\
\hline roots & 8.71 & 4.78 & 14.80 & 10.68 & 13.50 & 10.55 \\
\hline
\end{tabular}

${ }^{a}$ With $0.5 \mathrm{mg} \mathrm{kg}^{-1}$ ATR added to the soil; concentrations expressed on a dry weight basis. $-M$ and $+M$ represent uninoculated plants and inoculation with the mycorrhizal fungus $G$. etunicatum, respectively.

which might be taken up less than ATR or Cd individually. In a colonized plant more $\mathrm{Cd}$ and ATR could be sequestered in the root systems by binding to mycelium or adsorption on the roots $(19,27)$. AMF could also influence the uptake of ATR or $\mathrm{Cd}$ via mycorrhizosphere effects, whereby their mycelial systems in soil may influence the structure and activities of soil microbial assemblages (2). All of these effects should be taken into account when the interactions between ATR and Cd with mycorrhizal colonization are interpreted.

Although on examination we did not find any clear trends in the accumulation of the metabolites in maize roots or shoots, if we sum the concentrations of ATR and its metabolites together (Table 4), we can observe that AMF-inoculated roots accumulated more than did nonmycorrhizal roots. In contrast, inoculation caused a decrease in the concentrations of ATR and its metabolites together in the shoots compared with the nonmycorrhizal plants. For instance, the total content of ATR and its metabolites in inoculated roots was $1.3-1.8$ times higher than in uninoculated roots. The corresponding content in shoots showed an opposite trend, decreasing by $24.4-57.8 \%$ with inoculation. A general trend of enhanced accumulation of ATR in roots was identified with the coexistence of $\mathrm{Cd}$ irrespective of inoculation status. The total concentrations of ATR and its metabolites in mycorrhizal roots increased by 70.0 and $54.9 \%$ when the $\mathrm{Cd}$ concentrations in the soil were 1.0 and $5.0 \mathrm{mg}$ $\mathrm{kg}^{-1}$, respectively, compared to the control treatment without $\mathrm{Cd}$. The corresponding increases for nonmycorrhizal roots were 23.4 and $21.5 \%$. However, when the different metabolites were considered individually, they showed no consistent trends.

Mycorrhizal treatment and $\mathrm{Cd}$ application influenced the dissipation of ATR in the soil (Figure 2). Without colonization or in the treatment with an initial ATR concentration at $0.5 \mathrm{mg}$ $\mathrm{kg}^{-1}$, residual ATR did not differ significantly between bulk and rhizosphere soil. However, with mycorrhizal inoculation and an initial ATR application rate of $5.0 \mathrm{mg} \mathrm{kg}$.1, ATR was much higher in the rhizosphere than in the bulk soil. This may be attributed to either enhanced ATR transport from the bulk soil to the rhizosphere with the help of the fungal mycelium or the aggregation of ATR on root surfaces as a result of ATR binding to the mycelium or adsorbing on root surfaces $(16,24)$. Cadmium application also significantly decreased the residual concentrations of ATR in both the rhizosphere and bulk soil irrespective of inoculation treatment. The mechanisms for the effects of mycorrhizal colonization and $\mathrm{Cd}$ application on the dissipation of ATR are not clear and may be associated with increased microbial activity in the rhizosphere soil due to the AMF (11), formation of ATR-Cd complexes to enhance the uptake of ATR by plant roots, and formation of soil-bound residues by hyphal networks. The new interface of soil-plant interactions could also have substantial influences on ATR dissipation.
This study has contributed to our understanding of the role of AMF in pollutant uptake by plants as well and indicates the potential of plant-based strategies for remediation of soils cocontaminated with heavy metal and organic pollutants. However, we must bear in mind that our findings are based on the use of soils artificially spiked with Cd and ATR and incubated for a short time. Aged contaminants might exhibit some differences in behavior compared with freshly added pollutants, especially in pots in which root growth is restricted to a small volume of soil. Confirmation of the findings will require studies using field soils that have been contaminated for considerable periods of time.

\section{LITERATURE CITED}

(1) Sandrin, T. R.; Chech, A. M.; Maier, R. M. A rhamnolipid biosurfactant reduces cadmium toxicity during biodegradation of naphthalene. Appl. Environ. Microbiol. 2000, 66, 4585-4588.

(2) Smith, S. E.; Read, D. J. Mycorrhizal Symbiosis, 2nd ed.; Academic Press: London, U.K., 1997.

(3) Leyval, C.; Turnau, K.; Haselwandter, K. Effect of heavy metal pollution on mycorrhizal colonization and function: physiological, ecological and applied aspects. Mycorrhiza 1997, 7, 139153.

(4) Zhu, Y. G.; Christie, P.; Laidlaw, A. S. Uptake of Zn by arbuscular mycorhizal white clover from $\mathrm{Zn}$-contaminated soil. Chemosphere 2001, 42, 193-199.

(5) Chen, B. D.; Roos, P.; Borggaard, O. K.; Zhu, Y. G.; Jakobsen, I. Mycorrhiza and root hairs in barley enhance acquisition of phosphorus and uranium from phosphate rock but mycorrhiza decreases root to shoot uranium transfer. New Phytol. 2005, 165, $591-598$.

(6) Joner, E. J.; Leyval, C. Phytoremediation of organic pollutants using mycorrhizal plant: a new aspect of rhizosphere interactions. Agromomie 2003, 23, 495-502.

(7) Leyval, C.; Binet, P. Effect of polyaromatic hydrocarbons (PAHs) in soil on arbuscular mycorrhizal plants. J. Environ. Qual. 1998, 27, 402-407.

(8) Joner, E. J.; Leyval, C. Rhizosphere gradients of polycyclic aromatic hydrocarbon (PAH) dissipation in two industrial soils, and the impact of arbuscular mycorrhiza. Environ. Sci. Technol. 2003, 37, 2371-2375.

(9) Huang, H. L.; Zhang, S. Z.; Shan, X. Q.; Chen, B. D.; Zhu, Y. G.; Bell, N. J. B. Effect of arbuscular mycorrhizal fungus (Glomus caledonium) on the accumulation and metabolism of atrazine in maize (Zea mays L.) and atrazine dissipation in soil. Environ. Pollut. 2006, doi:10.1016/j.envpol.2006.07.001

(10) Li, X. L.; Christie, P. Changes in soil solution $\mathrm{Zn}$ and $\mathrm{pH}$ and uptake of $\mathrm{Zn}$ by arbuscular mycorrhizal red clover in $\mathrm{Zn}$ contaminated soil. Chemosphere 2001, 42, 201-207.

(11) Olsson, P. A.; Francis, R.; Read, D. J.; Söderström, B. Growth of arbuscular mycorrhizal mycelium in calcareous dune sand and its interaction with other soil microorganisms as estimated by measurement of specific fatty acids. Plant Soil 1998, 201, 9-16.

(12) Christie, P.; Li, X. L.; Chen, B. D. Arbuscular mycorrhiza can depress translocation of zinc to shoots of host plants in soils moderately polluted with zinc. Plant Soil 2004, 261, 209-217.

(13) Winkelmann, D. A.; Klaine, S. J. Degradation and bound residue formation of atrazine in a western Tennessee soil. Environ. Toxicol. Chem. 1991, 10, 335-345.

(14) Graymore, M.; Stagnitti, F.; Allison, G. Impacts of atrazine in aquatic ecosystems. Environ. Int. 2001, 26, 483-495.

(15) Landis, W. G.; Yu, M. H. Routes of exposure and modes of action. In Introduction to Environmental Toxicology. Impacts of Chemicals Upon Ecological Systems; Lewis Publishers: Boca Raton, FL, 1999; pp 93-130.

(16) Satarug, S.; Baker, J. R.; Urbenjapol, S.; Haswell-Elkins, M.; Reilly, P. E.; Williams, D. J.; Moore, M. R. A global perspective on cadmium pollution and toxicity in non-occupationally exposed population. Toxicol. Lett. 2003, 137, 65-83. 
(17) Blume, E.; Bischoff, M.; Moorman, T. B.; Turco, R. F. Degradation and binding of atrazine in surface and subsurface soils. J. Agric. Food Chem. 2004, 52, 7382-7388.

(18) Su, Y. H.; Zhu, Y. G. Bioconcentration of atrazine and chlorophenols into roots and shoots of rice seedlings, Environ. Pollut. 2006, 139, 32-39.

(19) Nedumpara, M. J.; Moorman, T. B.; Jayachandran, K. Effect of a vesicular-arbuscular mycorrhizal fungus (Glomus epigaeus) on herbicide uptake by roots. Biol. Fert. Soils 1999, 30, 75-82.

(20) Facundo, R. B.; Catherine, C.; Katarzyna, T.; Jean-Pierre, C.; Andrei, A. B.; Silvio, G.; Reto, J. S.; Vivienne, G. P. Cadmium accumulation and buffering of cadmium-induced stress by arbuscular mycorrhiza in three Pisum sativum L. genotypes. J. Exp. Bot. 2002, 53, 1177-1185.

(21) Phillips, J. M.; Hayman, D. S. Improved procedures for clearing and staining parasitic and vesicular-arbuscular mycorrhizal fungi for rapid assessment of infection. Trans. Br. Mycol. Soc. 1970, $55,158-161$.

(22) Wenger, K.; Bigler, L.; Suter, M. J.-F.; Schoünenberger, R.; Gupta, S. K.; Schulin, R. Effect of corn root exudates on the degradation of atrazine and its chlorinated metabolites in soils. J. Environ. Qual. 2005, 34, 2187-2196.

(23) Ana, M.; Alicia, M.; Viviana, C.; Nadia, V.; Juan, A. O.; Alicia, G. Influence of the insecticide dimethoate on arbuscular mycorrhizal colonization and growth in soybean plants. Int. Microbiol. 1999, 2, 43-45.

(24) Zhang, X. H.; Zhu, Y. G.; Lin, A. J.; Chen, B. D.; Smith, S. E.; Smith, F. A. Arbuscular mycorrhizal fungi can alleviate the adverse effects of chlorothalonil on Oryza sativa L. Chemosphere 2006, 64, 1627-1632.

(25) Grabec, I.; Bozidar, O.; Hudnic, V. A polarographic investigation on interactions between $\mathrm{Cu}(\mathrm{II})$ ions and natural degradation products of a herbicide atrazine. Electroanalysis 1994, 6, 908913.

(26) Manuela, M.; AgneÁs, H.; Jean-Pierre, B.; Maurice, L. Use of synergistic extraction for the study of atrazine/metal interactions. Anal. Chim. Acta 1998, 373, 161-165.

(27) Joner, E. J.; Leyval, C. Uptake of ${ }^{109} \mathrm{Cd}$ by roots and hyphae of a Glomus, mosseae/trifolium subterraneum mycorrhiza from soil amended with high and low concentrations of cadmium. New Phytol. 1997, 135, 353-360.

Received for review June 17, 2006. Revised manuscript received September 26, 2006. Accepted September 27, 2006. This work was funded by the National Natural Science Foundation of China (20677072) and the National Basic Research Program (2003CB415004).

JF061699G 